\title{
Affecting Factors of the Competitive Sports' Regional Differences in China
}

\author{
Lei Yao, Jingdong Chang* \\ School of Physical Education, Southwest University, Chongqing, China \\ Email: ${ }^{*}$ changlai@163.com
}

Received 29 December 2014; accepted 17 January 2015; published 23 January 2015

Copyright (C) 2015 by authors and Scientific Research Publishing Inc.

This work is licensed under the Creative Commons Attribution International License (CC BY). http://creativecommons.org/licenses/by/4.0/

(c) (i) Open Access

\begin{abstract}
National game is the highest level of comprehensive sports games in China which is competed by each province (city and autonomous region) as unitary units. As the imbalance of economy and population among different provinces (cities and autonomous regions), there are imbalance of competitive sports developments. Breaking through the traditional mode of regarding provinces (cities or autonomous regions) as the units for comparison and analysis, this research adopts the approach of comparing six regions in administrative districts and defining seven indicators as factors influencing Chinese regional competitive sports developments. Through the way of linear regression, this essay gradually chooses the factors which exert effects on Chinese competitive sports' regional differences. It is found that competitive strength, economical strength, in-team player, reserve player and on-the-job coach are the principal factors affecting Chinese competitive sports' regional differences. Meanwhile, the essay tends to provide references for balance development between regions on China by establishing regression equation MS $=1.601+1.159 \times$ XS3 + $0.300 \times$ XS1 + $0.2497 \times$ XS4 + $0.189 \times$ XS5 + $0.181 \times$ XS6 of Chinese competitive sports' regional differences.
\end{abstract}

\section{Keywords}

Competitive Sports, Regional Difference, National Game, Affecting Factors

\section{Introduction}

National game is short for the national games of the People's Republic of China which is the highest level and largest comprehensive sports game in China. The first game was held in Beijing in September 13 to October 3, 1959, holding every four years. Usually, it is held one year after the Olympic game (the time of first three games

"Corresponding author. 
is not fixed as the longest interval is ten years and the $7^{\text {th }}$ game is held after the interval of six years). At present, the events of national game are the same with Olympic Game except martial art which aims to train new athletes and select talents for the purpose of Olympic strategy. However, the performance is regarded as an important indicator of judging their sports and comprehensive strength by each province and city resulting in the intense competition and sometimes violating the original meaning of National Game. In order to arouse the enthusiasm of each province and city, General Administration of Sport of China proposed "bring Olympic medals into National Game” before Olympic Games in 1996, which means the medals got by athletes in Olympic Games representing China will be calculated in the next year's National Game as the score of this province. To generally reflect the affecting factors in the development of Chinese regional competitive sports, this research tries to analyze these affecting factors in the way of linear regression.

\section{Research Object}

According to the current administrative division, our country is divided into six regions including North China, northeast, East China, middle-south, southwest and northwest. Assuming the medals got by each region in the $10^{\text {th }}$ and $11^{\text {th }}$ National Games [1] [2] are related to the economic strength, population, competitive strength, the strength of in-team athletes, reserve athletes, on-the-job coaches and reserve coaches of each region, the author can build the following functional relation: Medals $=\mathrm{f}(\mathrm{GDP}$, POP, SPO, PLA, BPA, JOC, SPC) [3].

\section{The Analysis of Affecting Factors and Specific Observations}

\subsection{The Economic Strength of Regions (X1)}

It is generally believed that more financial resources and efforts can be invested in developing sports with the development of economy. The Gross Domestic Product (GDP) of each region is an indispensable indicator measuring the economic strength of regions by adopting the portion of regional GDP constituting in domestic GDP and regarding RMB as the units in the regional GDP (2005 and 2007).

\subsection{The Population (X2)}

If the probability of sports elite' distribution in China is stable, the result is that the more population the region has, the more likely the region finding many high-quality athletes which in turn improves the medals of this region. This essay adopts the share of regional population taking up in Chinese domestic population to measure the factor of population.

\subsection{The Competitive Strength (X3)}

The performance of Competition regions in National Games, on one hand reflects the sports strength of this region and on the other hand mirrors the sport tradition of this region. Therefore, this thesis adopts the share of total score of the $10^{\text {th }}$ session constituting the score of this session and the portion of total score of the $11^{\text {th }}$ session constituting the score of this session as variables to measure sport strength.

\subsection{The Strength of In-Team Athletes (X4)}

In-team athletes are the main force and the core parts of regional competitive sports. The share of the quantity of in-team athletes (2005 and 2007) constituting the gross was considered as the variables of measuring the strength of in-team athletes

\subsection{The Strength of Reserve Athletes (X5)}

The athletes of sport schools are the reserve strength of the development of each region's competitive sports, so the talent reserve is closely related to the development of regional competitive sports. The portion of quantity of athletes in regional sport schools (2005 and 2007) in the gross is regarded as the variable of measuring the reserve players.

\subsection{The Strength of On-the-Job Coaches (X6)}

On-the-job coaches are the main force of player cultivation and the core parts of regional competitive sports. 
The portion of the quantity of on-the-job coaches (2005 and 2007) constituting the gross is taken as the variables to measure the strength of regional on-the-job coaches.

\subsection{The Strength of Reserve Coaches (X7)}

The coaches of sport schools are the important supply resources of the first team coaches. The portion of the quantity of coaches in region sport schools (2005 and 2007) constituting the gross is regarded as the variables of measuring the strength of reserve coaches.

Through reasonable operation of these factors affecting the medals got by each region and considering the availability and validity of data in selecting indicators, it is intended to improve the feasibility of this study. In previous studies, most of them are conducted from the perspective of relative value of each indicator. As the events of each National Game are constantly changing and the total medals are changing correspondingly, as well as the domestic economy and population are changing while the total medals may not increase correspondingly, in order to ensure the comparability of the medals of and two National Games and eliminate the influence brought by these facts, this essay adopts the relative value of each indicator by transferring each indicator and calculating the portion of each indicators in each region, instead of using absolute data. The formula is $\mathrm{XS}_{\mathrm{i}}=$ $\mathrm{X}_{\mathrm{i}} / \Sigma \mathrm{i}=1,2,3 \cdots \mathrm{Xi} \times 100 \%$ and $\mathrm{i}$ represents each indicator [4] [5].

\section{The Origin of Model and Data}

GDP, POP, SPO, PLA, BPA, JOC and SPC are representing regional economic strength, population, competitive strength, in-team athletes, reserve athletes, on-the-job coaches and reserve coaches respectively. On the basis of medal ranking of the $10^{\text {th }}$ and $11^{\text {th }}$ National Games, regarding the each region's medal share(MS) of that session as dependent variables and each indicator of each factors as independent factors, this essay establish a linear model as following: $\mathrm{MS}=\alpha+\beta 1 \mathrm{XS} 1+\beta 2 \mathrm{XS} 2+\beta 3 \mathrm{XS} 3+\beta 4 \mathrm{XS} 4+\beta 5 \mathrm{X} 5+\beta 6 \mathrm{X} 6+\beta 7 \mathrm{X} 7$.

The data of medals of National Games come from the official website of National Games. The data of Gross Domestic Product and population are from China Statistical Yearbook. The data of competitive strength, in-team athletes, reserve athletes, on-the-job coaches and reserve coaches are from China's Social Statistical Yearbook.

\section{The Results of Empirical Analysis}

\subsection{Statistics Description and Correlation Analysis of Variables}

This essay mainly uses SPSS17.0 to analyze and deal with the data. In specific samples, the samples included in multiple regression analysis are 12 . The mean value of medal share (MS) is $16.67 \%$, the mean value of GDP share is $16.67 \%$, the mean value of POP share is $16.66 \%$, the mean value of SPO is $16.66 \%$, the mean value of PLA is $17.47 \%$, the mean value of BPA is $16.67 \%$, the mean value of JOC is $16.66 \%$ and the mean value of SPC is $16.67 \%$. In the correlation analysis of variables, the Correlation Coefficient Test of medal share (MS) and each independent variable reach significant level, among which the correlation of medal share and competitive strength and the strength of on-the-job coach is the highest (Table 1).

\subsection{The Empirical Results and Analysis}

With the Backward screening strategies, the author eventually establishes regression equation by three steps and selects 5 important explaining variables from seven explaining variables. The final modal $\mathrm{R}^{2}$ is 0.999 . The goodness-of-fit $\mathrm{R}^{2}$ after regulation is 0.998 . The value of $\mathrm{F}$ is 1012.20 and the corresponding probability $\mathrm{P}$ is approximately 0 . In terms of multiple collinearity diagnosis, the maximum of variance inflation factor (VIF) is 6.993 while the minimum is 1.174 . And there is a serious collinearity among each variable (Table 2).

The final regression equation is: medal share $=1.601+1.159 \times$ competitive strength + share of regional economy $+0.248 \times$ the strength of in-team athletes $+0.189 \times$ the strength of reserve athletes $+0.181 \times$ the strength of on-the-job coaches. That is MS $=1.601+1.159 \times \mathrm{XS} 3+0.300 \times \mathrm{XS} 1+0.2497 \times \mathrm{XS} 4+0.189 \times$ XS5 + 0.181 × XS6.

This model means the share of competitive strength, GDP, in-team athletes, reserve athletes and on-the-job coaches exert positive influences on medal share and the rise of corresponding variables share could increase medal share. The share of competitive strength of a region increases one unit, then the medal share increases 
Table 1. Statistics description and correlation analysis of data from samples.

\begin{tabular}{|c|c|c|c|c|c|c|c|c|c|c|}
\hline \multirow{2}{*}{ Variables } & \multicolumn{3}{|c|}{ Statistics description } & \multicolumn{7}{|c|}{ Correlation analysis } \\
\hline & M & V & $\mathrm{N}$ & MS & RE & $\mathrm{RP}$ & CS & SITA & SRA & SOJC \\
\hline MS & 16.67 & 9.41 & 12 & & & & & & & \\
\hline $\mathrm{RE}$ & 16.67 & 8.19 & 12 & $0.784^{* *}$ & & & & & & \\
\hline $\mathrm{RP}$ & 16.59 & 6.05 & 12 & $0.542^{*}$ & $0.855^{* *}$ & & & & & \\
\hline CS & 16.76 & 8.65 & 12 & $0.996^{* *}$ & $0.827^{* *}$ & $0.579^{*}$ & & & & \\
\hline SITA & 17.47 & 8.89 & 12 & $0.625^{*}$ & $0.602^{*}$ & $0.656^{*}$ & $0.630^{*}$ & & & \\
\hline SRA & 16.14 & 5.82 & 12 & $0.609^{*}$ & 0.404 & 0.416 & $0.602^{*}$ & $0.837^{* *}$ & & \\
\hline SOJC & 16.31 & 6.20 & 12 & $0.948^{* *}$ & $0.797^{* *}$ & $0.617^{*}$ & $0.952^{* *}$ & $0.802^{* *}$ & $0.760^{* *}$ & \\
\hline SRC & 16.83 & 5.98 & 12 & $0.830^{* *}$ & 0.572 & 0.286 & $0.805^{* *}$ & $0.641^{*}$ & $0.562^{*}$ & $0.824^{* *}$ \\
\hline
\end{tabular}

${ }^{* * *}$ Related significant level 0.01; ${ }^{*}$ Related significant level 0.05; MS = medal share; RE = regional economy; RP = regional population; CS = competitive strength; SITA = the strength in-team athletes; SRA = the strength of reserve athletes; SOJC = the strength of on-the-job coaches; SRC = the strength of reserve coaches.

Table 2. The final estimated results of the mode.

\begin{tabular}{ccccccc}
\hline Variables & R.C & S.E & S.R.C & Sig & Tol & VIF \\
\hline (Constant) & 1.601 & 0.078 & 0.127 & & & \\
XS3 & 1.159 & 0.071 & 1.066 & 0.000 & 0.033 & 6.993 \\
XS1 & 0.300 & 0.051 & 0.262 & 0.004 & 0.070 & 6.230 \\
XS4 & 0.249 & 0.060 & 0.160 & 0.014 & 0.096 & 2.405 \\
XS5 & 0.189 & 0.046 & 0.120 & 0.015 & 0.162 & 1.174 \\
XS6 & 0.181 & 0.124 & 0.003 & 0.007 & 0.021 & 1.436 \\
\hline
\end{tabular}

1.159\%; the GDP share increases one unit, then the medal share increases $0.300 \%$; the share of in-team athletes increases one unit, then the medal share increases $0.249 \%$; the share of reserve athletes increases one unit, then the medal share increased $0.189 \%$; the share of on-the-job coaches increases one unit, then the medal share increases $0.181 \%$.

\section{Conclusions}

Competitive strength, economic strength, in-team athletes, reserve athletes and on-the-job coaches have great influences on the development of region's competitive sports. The more developed the economy is, the stronger the competitive strength is and the better performance the regional competitive sports could have in National Games. Athletes and coaches are two main parts of competitive sports. In order to realize the connection of competitive sports' development links, each region needs to be equipped with sufficient in-team athletes and reserve talents. In this research, regional population is deleted which presents that the population cannot improve the competitive sports. Developing economy, reserve excellent athletes and coaches so as to improve the strength of competitive sports are paramount for fostering regional competitive sports.

There are some problems needed to be discussed. According to convention, coaches and athletes are principal factors affecting medal share, however, in the establishment of regression modal, the factors of reserve coaches are deleted which may result from the unsound statistics data. Currently, the detailed statistics about relevant sports personnel are recorded from 2005 while the previous data have not calculated systematically. Although Sports Yearbook has published the data of 60 years (38 volumes until 2009), the relevant information is not continuous as that in China Statistical Yearbook.

The $11^{\text {th }}$ National Game of 2009 had achieved a great success which left a vast variety of topics worth discus- 
sion and those topics promoted the implement of this research. Nowadays, China focuses on the sports model of "whole country system" and economic development is the solid base of the operation of this system. Competitive sports are able to develop only if the economy prospers and financial resources are invested to train reserve talents positively.

\section{References}

[1] http://baike.baidu.com/view/1870646.html

[2] http://www.shandong2009.cn/bms/xcbb/200910/t20091028_5044675.htm

[3] Deng, Y.L. (2007) Analysis on Olympics Host Country Effects and of the Competition Preparation for Chinese Delegation. China Sport Science and Technology, 43, 3-6.

[4] Wang, Y.P., Xu, J. and Zhang, Y.Y. (2008) Empirical Analysis on Factors Affecting Olympics Medal Count. Statistical Research, 25, 57.

[5] Xiong, Q. (2009) Analysis on Factors Affecting the Olympic Medal Count. Statistical Thinktank, 26, 45-49. 
Scientific Research Publishing (SCIRP) is one of the largest Open Access journal publishers. It is currently publishing more than 200 open access, online, peer-reviewed journals covering a wide range of academic disciplines. SCIRP serves the worldwide academic communities and contributes to the progress and application of science with its publication.

Other selected journals from SCIRP are listed as below. Submit your manuscript to us via either submit@scirp.org or Online Submission Portal.
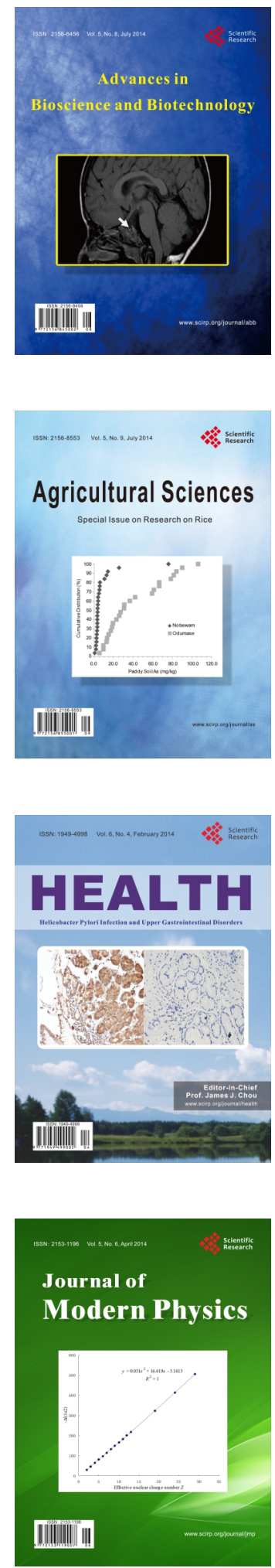
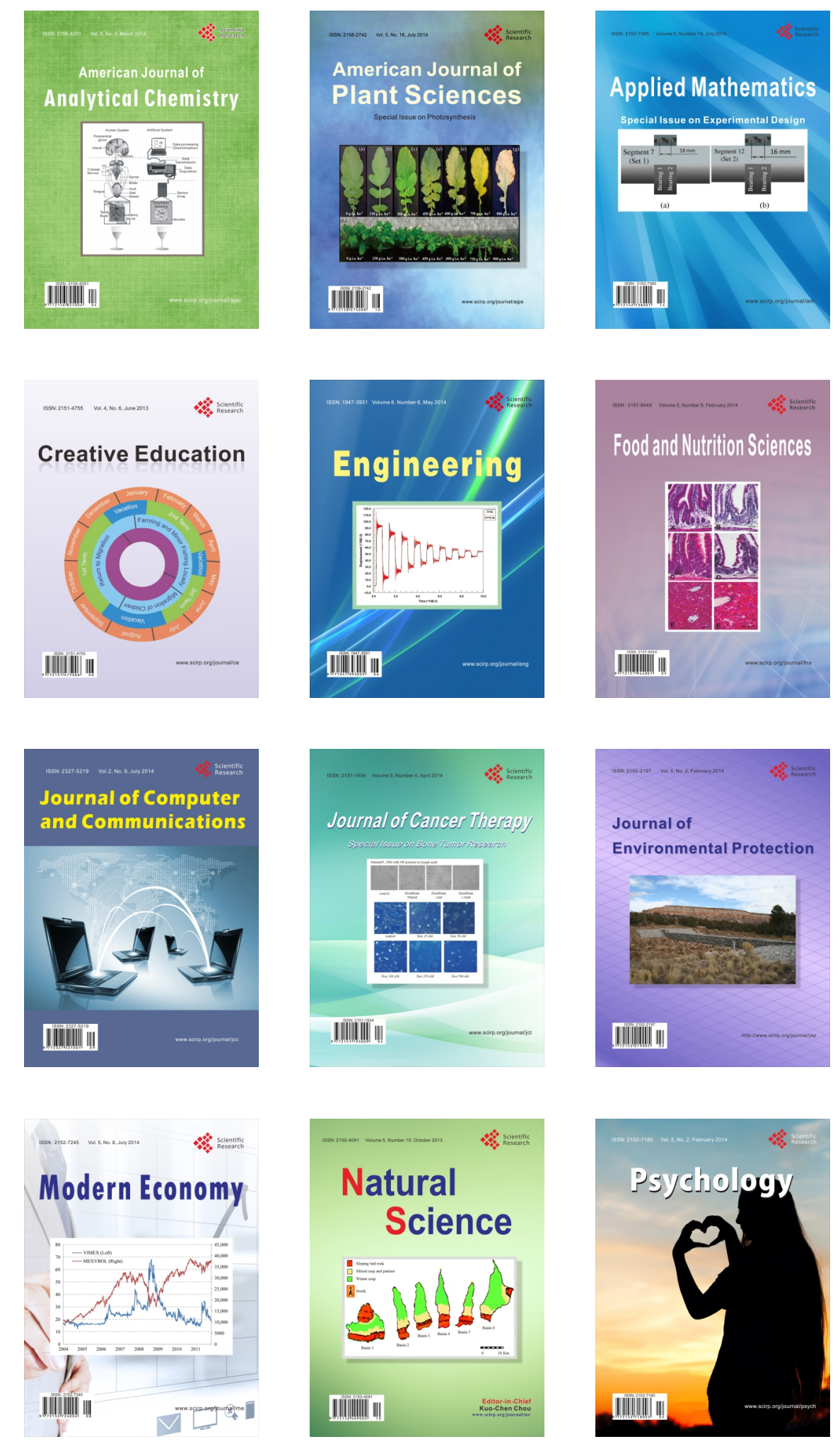